\title{
Kajian dan Komparasi Teoritis Metode Prediksi Tekanan Pori: Metode Eaton dan Metode Bower
}

\author{
Muhammad Arif Budiman, Dwa Desa Warnana, Firman Syaifuddin \\ Departemen Teknik Geofisika, Fakultas Teknik Sipil dan Perencanaan, Institut Teknologi Sepuluh Nopember (ITS) \\ e-mail:dwa_desa@geofisika.its.ac.id; firman@geofisika.its.ac.id
}

\begin{abstract}
Abstrak-Prediksi tekanan pori sebelum proses pengeboran menjadi hal yang sangat penting karena banyaknya berat lumpur (Mud Weight) dapat direpresentasikan ketika melakukan pengeboran. Penelitian ini akan membandingkan dua jenis metode yang sering digunakan dalam perhitungan prediksi tekanan pori, yaitu: Metode Eaton, dan Metode Bowers. Kedua metode ini akan dibandingkan keakuratannya berdasarkan parameter-parameter yang dimasukkan untuk memprediksi nilai tekanan pori. Hasil penelitian menunjukkan bahwa metode Bower dan metode Eaton sama-sama memiliki kelebihan dan kekurangannya masing-masing. Pemilihan metode yang digunakan diantara kedua metode tersebut bisa dilakukan berdasarkan kondisi geologi dan ketersediaan data yang ada. Walaupun begitu, keakuratan dalam prediksi dapat dicapai dengan data yang seadanya dengan cara penggabungan metode Eaton dan metode Bower.
\end{abstract}

Kata Kunci-Bower, Eaton, Tekanan Pori.

\section{PENDAHULUAN}

$\mathrm{D}$ ALAM proses eksplorasi, pemahaman terhadap karakterisasi sifat fisik batuan dan fluida pengisi batuan di daerah ini sangat penting untuk menentukan berhasil atau tidaknya suatu kegiatan eksplorasi. Kaitannya dengan kegiatan pengeboran, pengetahuan atas sifat fisik dan fluida batuan tersebut dapat membantu untuk mendeteksi keberadaan Overpressure, sehingga resiko kecelakaan pengeboran dapat dihindari dan tindakan penanggulangan dapat lebih dipersiapkan dengan lebih baik.

Dalam memprediksi tekanan pori telah berkembang beberapa metode prediksi, salah satunya yaitu metode turunan dari data sonic. Metode-metode tersebut mengutamakan hasil prediksi yang akurat dan meminimalkan kesalahan dalam operasi pengeboran. Metode-metode prediksi tekanan pori yang berkembang adalah dengan menggunakan data kecepatan yang diturunkan dari data seismik, yang dipopulerkan oleh [1] dan [2]. Metode [1] diperkenalkan sebagai persamaan empiris dengan studi kasus di Gulf of Mexico [1]. Sebagai metode empiris, metode Eaton menggunakan semua data yang ada untuk mendeteksi Overpressure yang disebabkan Karena mekanisme loading sehingga hasil perhitungan metode ini mendekati nilai data kontrol yang ada. Namun, persamaan Eaton tidak memperhitungkan Overpressure yang disebabkan oleh mekanisme unloading, sehingga terkadang nilai tekanan pori yang terukur lebih rendah dari nilai yang seharusnya. Maka dari itu, metode yang dikembangkan oleh [2] menjadi solusi dari ketidakakuratan metode Eaton ini. Sayangnya, untuk beberapa kasus metode Bower dianggap tidak bagus.

Berdasarkan hal tersebut, studi ini dilakukan untuk membandingkan dua metode secara teoritis yang paling optimal untuk memprediksi tekanan pori dan membandingkannya dengan data pengukuran tekanan langsung.

\section{TINJAUAN PUSTAKA}

\section{A. Prinsip Terzaghi}

Nilai tekanan pori diestimasi dengan melihat hubungan antara porositas batuan dan, tekanan overburden, dan tekanan efektif. Hubungan ini dijelaskan Terzaghi dalam persamaan sebagai berikut :

$$
\sigma=p p+\sigma^{\prime}
$$

Dimana:

$\sigma \quad:$ Tekanan overburden (Psi)

$p p$ : Tekanan pori (Psi)

$\sigma^{\prime} \quad$ : Tekanan efektif (Psi)

Dari formula tersebut dapat dikatakan bahwa jika suatu sedimen terkompaksi secara normal dibawah lapisan sedimen yang terdepositkan diatasnya dan porositas batuannya berkurang, maka nilai effective stress (kontak antar butir-butir dalam buatuan tersebut pada arah vertikal) akan meningkat.

\section{B. Tekanan Overburden}

Tekanan overburden atau Overburden stress adalah tekanan yang terjadi karena pembebanan sedimen dan materi-materi yang ada di atas suatu formasi [3]. Secara matematis, tekanan overburden dapat dihitung dengan persamaan (2):

$$
\sigma=\rho g Z
$$

Dimana:

$\sigma:$ Tekanan overburden $(\mathrm{Pa})$

$\rho$ : Densitas bulk $\left(\mathrm{kg} / \mathrm{m}^{3}\right)$

$g$ : Percepatan gravitasi $\left(\mathrm{m} / \mathrm{s}^{2}\right)$

$z:$ Ketebalan sedimen (meter)

\section{Tekanan Normal Hidrostatik}

Tekanan hidrostatik adalah tekanan yang disebabkan oleh berat fluida dalam sebuah kolom batuan. Sebuah tekanan pada batuan dianggap overpressure jika nilainya melebihi nilai tekanan normal hidrostatiknya. Persamaan untuk menentukan nilai tekanan ini, dituliskan dalam persamaan (2.3):

$$
P=\rho g h
$$


Dimana:

$P$ : Tekanan normal hidrostatik $(\mathrm{Pa})$

$\rho$ : Densitas fluida $\left(\mathrm{kg} / \mathrm{m}^{3}\right)$

$g$ : Percepatan gravitasi $\left(\mathrm{m} / \mathrm{s}^{2}\right)$

$Z$ : Ketebalan kolom fluida pada suatu batuan (meter)

\section{Metode Eaton}

Dalam teorinya, Eaton menjelaskan jika mayoritas tekanan bawah permukaan berasal dari pengaruh overburden atau disebut dengan primary Overpressure [1]. Overpressure ini terjadi karena penimbunan akibat cepatnya suplay sedimen yang berfungsi sebagai seal sehingga fluida yang ada sebelumnya tidak dapat bergerak. Cairan yang terpreangkap dalam sebuah kolom batuan akan memberikan balasan sebagai aksi reaksi terhadap energi yang datang akibat beban yang makin bertambah di atasnya yang disebut Overpressure primer.

Untuk melakukan prediksi tekanan pori dengan menggunakan metode ini pada suatu daerah tertentu cukup menggunakan data hasil pengukuran geofisika seperti data seismik dan data sonic. Data seismik didapat dari hasil survey seismik pada wilayah tersebut dan data sonic bisa kita gunakan dari sumur-sumur yang sudah ada di sekitar lokasi yang akan kita prediksi. Berikut rumusan singkat dari teori Eaton yang biasa digunakan para ahli geofisika dalam memprediksi tekanan pori suatu prospek yang akan dibor

Seperti yang telah disebutkan, Eaton menggunakan sematamata data geofisika untuk melakukan prediksi tekanan pori suatu formasi. Persamaan Eaton secara sederhana dituliskan sebagai berikut:

$$
P P=\sigma-\left[(\sigma-N h y d) *\left(\frac{V_{\text {interval }}}{V_{\text {Interval }} N C T}\right)^{x}\right]
$$

Dimana:

$\begin{array}{ll}P P & : \text { Tekanan pori (Psi), } \\ \sigma & : \text { Tekanan overburden (Psi), } \\ \text { Nhyd } & : \text { Tekanan normal hidrostatik, (Psi) } \\ V_{\text {interval }} & : \text { Kecepatan interval yang terukur }(\mathrm{m} / \mathrm{s}), \\ V_{\text {Interval }} \text { NCT } & : \text { Kecepatan interval pada normal } \\ X & \text { compaction trend (NCT) }(\mathrm{m} / \mathrm{s}), \\ & : \text { Koefisien empiris Eaton }(1.2-3) .\end{array}$

Dari persamaan (4) di atas, Eaton mengandalkan kecepatan interval dari data sonic untuk mendapatkan nilai kecepatan pada normal compaction trend (NCT). NCT ini nantinya akan digunakan untuk menghitung tekanan pori pada lokasi prediksi dengan menggunakan pendekatan Eaton.

\section{E. Metode Bower}

Metode yang dikembangkan oleh Glenn L. Bowers pada tahun 1995 ini pada dasarnya menggunakan konsep yang hampir sama dengan metode Eaton, yaitu persamaan untuk menentukan nilai Effective Stressnya [2]. Namun persamaan yang dikemukakan oleh Bower ini lebih baik dibandingkan dengan Eaton, Karena persamaan Bower lebih mempertimbangkan faktor unloading. Karenanya, membuat metode Bower ini lebih cocok untuk memprediksi formasi yang memiliki nilai tekanan pori yang tinggi.

Dalam persamaan untuk menentukan nilai Effective Stress pada kasus mekanisme loading, Bowers mengemukakan persamaan yang menghubungkan antara velocity interval dan Effective Stress. Persamaan Bowers secara sederhana dituliskan sebagai berikut:

$$
V_{\text {Interval }}=V_{o}+A \sigma^{\prime}
$$

Dimana:

$V_{\text {interval }}:$ Velocity interval yang terukur $(\mathrm{m} / \mathrm{s})$,

$\sigma^{\prime} \quad$ : Tekanan efektif (Psi),

$A$ dan $B$ : Koefisien empiris Bower,

$V_{o} \quad:$ Kecepatan interval pada mudline $(\mathrm{m} / \mathrm{s})$,

Untuk kasus unloading, Bower juga merumuskan persamaan empiris dengan modifikasi dari persamaan 5 sebagai berikut:

$$
V_{\text {Interval }}=V_{o}+A\left[\sigma_{\max }^{\prime}\left(\frac{\sigma^{\prime}}{\sigma^{\prime} \max }\right)^{\frac{1}{U}}\right]^{B}
$$

Dimana:

$V_{\text {interval }}$ : Velocity interval yang terukur $(\mathrm{m} / \mathrm{s})$,

$\sigma^{\prime} \quad$ : Tekanan efektif (Psi),

$\sigma_{\text {max }}^{\prime} \quad$ : Tekanan efektif maksimal (Psi),

$A$ dan $B$ : Koefisien empiris Bower,

$V_{o} \quad:$ Kecepatan interval pada mudline $(\mathrm{m} / \mathrm{s})$,

$\mathrm{U} \quad$ : Koefisian empiris Bower pada kasus unloading $(3-8)$,

\section{METODOLOGI PENELITIAN}

Pada penelitian ini akan dibahas persamaan Eaton dan Bower secara teoritis. Kemudian, dilanjutkan dengan contoh data hasil perbandingan antara metode Eaton dan metode Bower. Adapun data yang dibahas pada penelitian ini berasal dari wireline logging di daerah Delta Niger. Data di daerah tersebut sudah diolah dan dipublikasi oleh Anggi Wibowo dan Abdul Haris pada tahun 2015. Pada data tersebut, log kecepatan gelombang-p (Vp) akan digunakan sebagai acuan untuk merekonstruksi Normal Compaction Trend, log densitas yang akan digunakan sebagai input untuk membentuk nilai tekanan overburden, dan untuk membentuk nilai tekanan normal hidrostatik digunakan acuan dasar dari densitas fluida air sebesar $1 \mathrm{gr} / \mathrm{cc}$. Data pengukuran tekanan langsung hanya terdapat pada daerah tertentu. Untuk koefisien empiris Bower A dan B didapatkan dari crossplot antara effective stress hasil pengukuran tekanan langsung dengan velocity interval, dengan nilai A sebesar 4.536731 dan nilai B sebesar 0.720987.

Setelah data-data yang dibutuhkan terkumpul seperti tekanan overburden, tekanan normal hidrostatik, velocity interval, dan velocity NCT, persamaan Eaton digunakan untuk mendapatkan nilai tekanan porinya.

Untuk prediksi tekanan pori metode Bower, data yang digunakan lebih sedikit jika dibandingkan dengan Eaton, yaitu velocity interval, tekanan overburden, dan koefisien empiris A dan B.

\section{HASIL DAN ANALISA}

Persamaan Eaton yang dirumuskan pada persamaan 4 menggunakan pendekatan terhadap tekanan efektif untuk kemudian dikalkulasi nilai tekanan porinya dari hasil pengurangan tekanan overburden dan tekanan efektif. 
Persamaan ini secara sederhana menghitung nilai tekanan efektif normal dan mengkalikannya dengan data kecepatan interval yang terukur per kecepatan interval yang seharusnya. Hal tersebut dapat dirumuskan menjadi persamaan 7:

$$
\sigma^{\prime}=\left[\left(\sigma_{\text {normal }}^{\prime}\right) *\left(\frac{V_{\text {interval }}}{V_{\text {Interval }} N C T}\right)^{x}\right]
$$

\section{Dimana:}

$$
\begin{array}{ll}
\sigma^{\prime} & : \text { Tekanan efektif (Psi), } \\
\sigma^{\prime}{ }_{n o r m a l} & : \text { Tekanan efektif pada keadaan normal (Psi), } \\
V_{\text {interval }} & : \text { Kecepatan interval yang terukur }(\mathrm{m} / \mathrm{s}), \\
V_{\text {Interval }} \text { NCT } & : \text { Kecepatan interval pada normal } \\
& \text { compaction trend (NCT) }(\mathrm{m} / \mathrm{s}), \\
X & : \text { Koefisien empiris Eaton. }
\end{array}
$$

Persamaan 7 di atas menghitung nilai tekanan efektif yang terbelokkan (deflect) dari nilai tekanan efektif keadaan normal dengan cara mengkalikannya dengan kecepatan interval terukur dibagi kecepatan interval pada keadaan normal. Hasil pembagian dari kecepatan interval yang terukur dan kecepatan interval pada keadaan normal ini kemudian dipangkatkan dengan koefisien empiris Eaton yaitu X. Sehingga jika suatu batuan terkompaksi dengan normal, maka nilai kecepatan interval yang terukur akan sama dengan nilai kecepatan interval pada keadaan normal. Yang mengakibatkan nilai tekanan efektif akan sama dengan nilai tekanan efektif pada keadaan normal.

Untuk metode Bower, pendekatan yang dilakukan untuk mendapatkan nilai tekanan porinya juga sama seperti metode Eaton yaitu pada tekanan efektifnya. Perbedaannya ialah metode Bower merumuskan hubungan antara tekanan efektif dengan kecepatan interval seperti pada persamaan 5. Dalam hubungan antara tekanan efektif dan kecepatan interval, persamaan Bower memiliki koefisin empiris A dan B. Koefisien ini didapatkan dari hasil cross-plot antara tekanan efektif dan kecepatan interval. Namun mendapatkan nilai tekanan efektif untuk keperluan cross-plot membutuhkan data pengukuran tekanan langsung agar didapatkan nilai koefisien A dan B yang akurat. Jika tidak, hasil persamaan ini bisa menjadi tidak valid.

Metode Bower juga memiliki persamaan untuk kasus unloading. Untuk kasus unloading, tekanan efektif pada suatu batuan akan berkurang sehingga nilai tekanan pori yang dihasilkan akan mendekati nilai tekanan overburden. Untuk itu, Bower merumuskan persamaan untuk kasus unloading pada persamaan 6. Secara sederhana, persamaan Bower untuk kasus unloading menghitung tekanan efektif seperti pada persamaan 5. Kemudian, hasil tersebut dikalkulasi kembali dengan nilai tekanan efektif maksimal dan koefisien Bower U sehingga nilai tekanan efektifnya terbelokkan menjadi semakin menurun. Akibat dari penurunan nilai tekanna efektif ini, nilai tekanan pori menjadi semakin naik mendekati nilai tekanan overburden.

Sebagai metode empiris, metode Eaton dan Bower memiliki kelebihan dan kekurangannya masing-masing. Metode Eaton misalnya, memiliki kelebihan dimana nilai untuk menghitung tekanan pori tidak perlu memasukkan nilai hasil pengukuran tekanan tekanan porinya tidak cocok pada kasus unloading. Untuk metode Bower, metode ini memiliki kelebihan dimana nilai tekanan pori yang terhitung bisa cocok untuk kasus unloading atau kasus dengan nilai tekanan pori yang tinggi. Kekurangannya, untuk mendapatkan koefisien empiris A dan B dibutuhkan data pengukuran tekanan langsung di formasi geologi yang dituju. Jika formasi geologi yang dituju lebih dari satu, maka diharuskan memiliki data pengukuran tekanan langsung di tiap formasi geologi yang dituju. Hal ini dilakukan karena pada persamaan Bower, koefisien A dan B merupakan nilai yang sangat sensitif. Sehingga jika nilai A dan B tidak tepat, maka nilai tekanan pori yang dihasilkan tidak akan tepat juga.

Data hasil prediksi tekanan pori di daerah Delta Niger dapat dijadikan sebagai contoh nyata dalam komparasi metode Eaton dan metode Bower

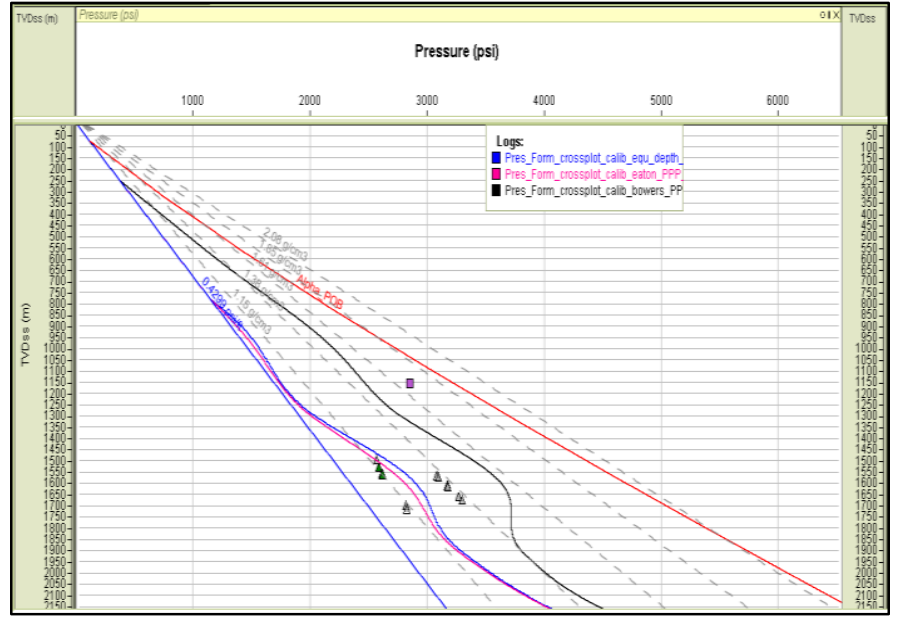

Gambar 1. Hasil tekanan pori di daerah Delta Niger berdasarkan Metode Equivalent Depth (garis biru), Metode Eaton (garis ungu), dan Metode Bowers (garis hitam). Gambar segitiga merupakan data tekanan hasil pengukuran langsung. (Haris dan Wibowo, 2015)

Pada gambar 1 di atas, dapat terlihat bahwa nilai prediksi tekanan pori menggunakan metode Eaton cocok dengan data pengukuran tekanan langsung pada kedalaman $1500-1600 \mathrm{~m}$. Namun pada kedalaman 1600 - 1700 m nilai prediksi dari metode Eaton tersebut tidak cocok dengan data pengukuran tekanan langsung. Hal ini karena metode Eaton tidak cocok untuk digunakan pada kasus unloading atau tekanan pori yang tinggi. Sehingga pada kedalaman $1600-1700 \mathrm{~m}$, hasil prediksi tekanan pori menggunakan metode Bower dinilai lebih cocok karena dapat memprediksi nilai tekanan pori yang tinggi. Walaupun pada kedalaman tersebut terdapat perbedaan antara prediksi metode Bower dan data pengukuran tekanan langsung sebesar 200 - 400 Psi, metode Bower dinilai lebih mampu memprediksi berapa nilai mud weight yang optimal untuk dilakukan pengeboran pada kedalaman tersebut. Namun, pada kedalaman 250 - 1550 m nilai tekanan pori menjadi tidak akurat. Hal ini dikarenakan koefisien empiris A dan B pada metode Bower didapatkan hanya dari cross-plot antara kecepatan interval dan data pengukuran tekanan langsung pada kedalaman $1450-1750 \mathrm{~m}$. Sehingga nilai koefisien A dan B yang akan dimasukkan pada persamaan metode Bower menjadi kurang akurat.

Adapun perlakuan pada tiap metode, dapat dilihat pada tabel. 1 di bawah ini: 
Tabel 1.

Perlakukan antara tiap metode

\begin{tabular}{cll}
\hline \hline Parameter & \multicolumn{1}{c}{ Metode Bower } & \multicolumn{1}{c}{ Metode Eaton } \\
\hline Data log Vp & Dapat digunakan & Dapat digunakan \\
Data log & Digunakan dalam & $\begin{array}{l}\text { Digunakan dalam } \\
\text { perhitungan }\end{array}$ \\
$\begin{array}{c}\text { Densitas } \\
\text { Normal }\end{array}$ & Tidak menggunakan NCT & Menggunakan NCT \\
$\begin{array}{c}\text { Compaction } \\
\text { Trend }\end{array}$ & & \\
$\begin{array}{c}\text { Pengukuran } \\
\text { Tekanan }\end{array}$ & Digunakan dalam & $\begin{array}{l}\text { Tidak digunakan dalam } \\
\text { perhitungan }\end{array}$ \\
$\begin{array}{c}\text { Langsung } \\
\text { Koefisien } \\
\text { empiris }\end{array}$ & A dan B & $\mathrm{X}$ \\
\hline \hline
\end{tabular}

Meskipun begitu, dibalik kekurangan dan kelebihan masing-masing metode. Untuk dapat memaksimalkan keakuratan prediksi tekanan pori menggunakan data yang minim, metode tersebut dapat digabungkan. Sebagai contoh, jika data tekanan hasil pengukuran tekanan langsung hanya diketahui di formasi tertentu yang mengalami unloading, sedangkanya di formasi lain hanya terdapat data berat lumpur (mud weight), maka metode Bower unloading akan sangat cocok untuk digunakan pada formasi yang mengalami unloading tersebut. Untuk formasi lainnya digunakan metode Eaton dengan berat lumpur sebagai data kontrol. Hal ini dilakukan karena nilai tekanan pori unloading atau tinggi akan lebih cocok jika digunakan metode Bower, terlebih karena data tekanan hasil pengukuran tekanan langsung hanya diketahui pada formasi tertentu. Sedangkan, metode Eaton sangat cocok untuk memprediksi nilai tekanan pori tanpa menggunakan data tekanan hasil pengukuran langsung sebagai input dalam perhitungan. Hal ini membuat metode Eaton lebih efisien dalam memasukkan parameter untuk melakukan prediksi tekanan pori di formasi geologi lainnya.

\section{KESIMPULAN/RINGKASAN}

Dari penelitian teoritis yang telah dilakukan dan contoh data yang ada, dapat diambil kesimpulan bahwa baik metode Eaton dan metode Bower memiliki kekurangan dan kelebihan masing-masing. Untuk menutupi kekurangan masing-masing metode, kedua metode tersebut dapat digabungkan dalam kasus-kasus tertentu. Sehingga dapat memaksimalkan keakuratan prediksi tekanan pori.

\section{DAFTAR PUSTAKA}

[1] B. A. Eaton, "The Equation for Geopressure Prediction from Well Logs," J. SPE AIME, pp. 1-5, 1975.

[2] G. L. Bowers, "Pore Pressure Estimation From Velocity Data: Accounting For Overpressure Mechanisms Besides Undercompaction," SPE Drill. Complet., pp. 3-7, 1995.

[3] A. M. Ramdhan, "OVERPRESSURE IN INDONESIA'S SEDIMENTARY BASINS VOLUME 1: THE LOWER KUTAI BASIN," vol. 1, no. 3, 2017. 